Check for updates

Cite this: Phys. Chem. Chem. Phys., 2017, 19, 25927
Received 5th June 2017,

Accepted 6th September 2017

DOI: $10.1039 / c 7 c p 03770 h$

rsc.li/pccp

\section{New insights into single-compound and binary adsorption of copper and lead ions on a treated sea mango shell: experimental and theoretical studies}

\author{
Lotfi Sellaoui, (D)*a Felycia Edi Soetaredjo, ${ }^{\mathrm{b}}$ Suryadi Ismadji, ${ }^{\mathrm{b}}$ Éder Cláudio Lima, ${ }^{\mathrm{c}}$ \\ Guilherme L. Dotto, ${ }^{d}$ Abdelmottaleb Ben Lamine ${ }^{a}$ and Alessandro Erto ${ }^{e}$
}

\begin{abstract}
Herein, adsorption isotherms of $\mathrm{Pb}(\|)$ and $\mathrm{Cu}(I)$ ions on treated sea mango fruit in both single-compound and binary systems were experimentally realized at different temperatures in the range of $30-50{ }^{\circ} \mathrm{C}$. Experimental results show that adsorption of $\mathrm{Pb}(॥)$ was more as compared to that of $\mathrm{Cu}(\|)$ ions; however, for both ions, a significant reduction in the adsorption capacity was observed in the binary system as compared to that in the single-compound systems. Moreover, under all the investigated conditions, adsorption seems to be promoted by an increase in temperature. To understand and interpret the experimental evidences, the Hill and competitive Hill models developed on the basis of the grand canonical ensemble were applied for the analysis of adsorption equilibrium data. These models contain some physicochemical parameters that allow an exhaustive analysis of the dynamics of single-compound and binary adsorptions. Based on the fitting results, in particular, through the evaluation of the number of ions bonded per site ( $n$ and $n_{i}$ ), it was found that lead and copper ions interacted by inclined and horizontal positions on treated sea mango in single-compound and binary systems, respectively. In addition, based on the same parameters, a significant interaction between ions was retrieved. A study focused on the saturation adsorption capacity in single-compound and binary systems affirmed that the adsorbent was more selective for lead than for copper. The reduction of the adsorbed capacity ratio between the binary and single-compound systems (i.e. $Q_{b} / Q_{s}$ ) explained and confirmed that an inhibition effect between copper and lead ions at the same receptor site occurred. Finally, based on the energetic investigations, it was deduced that the adsorption energy represented the dominant factor promoting the greater adsorption of lead than that of copper in both systems.
\end{abstract}

\section{Introduction}

Water pollution is one of the biggest problems that humans face today. In some areas of the world, the clean water supplies for human consumption have become scarcer and scarcer due to the accidental presence of different pollutants discharged by

\footnotetext{
${ }^{a}$ Unité de Recherche de Physique Quantique, UR 11 ES 54, Université de Monastir, Faculté des Sciences de Monastir, 5000 Monastir, Tunisia. E-mail: sellaouilotfi@yahoo.fr

${ }^{b}$ Department of Chemical Engineering, Widya Mandala Surabaya Catholic University, 601-14 Surabaya, Indonesia

${ }^{c}$ Institute of Chemistry, Federal University of Rio Grande do Sul, UFRGS, Porto Alegre, RS, Brazil

${ }^{d}$ Environmental Processes Laboratory, Chemical Engineering Department, Federal University of Santa Maria-UFSM, 1000, Roraima Avenue, 97105-900 Santa Maria, RS, Brazil

${ }^{e}$ Dipartimento di Ingegneria Chimica, dei Materiali e della Produzione Industriale, Università di Napoli Federico II, P.leTecchio, 80, 80125 Napoli, Italy
}

industrial or human activities. Industrial activities produce and release a large amount of wastewater during the processing of raw materials into valuable products. Most of the industrial wastewater contains toxic chemicals; therefore, a proper wastewater treatment facility is required to remove hazardous substances from the wastewater before discharging it. ${ }^{1}$ Heavy metals are among the most toxic chemicals usually found in wastewater. In general, they are highly threatening to living organisms due to their bio-accumulative behaviour, high toxicity, persistence in nature, and non-biodegradability. The available conventional technologies for the removal of heavy metals from industrial effluents are chemical precipitation, coagulation, reverse osmosis, electro dialysis, ultra-filtration, bio-remediation, phytoremediation, solvent extraction, and adsorption. ${ }^{2-6}$ Among the available methods, adsorption is a cost-effective, simple, reliable, and environmentally benign process for the elimination of heavy metals from water and wastewater. While dealing with the adsorption processes, the selection of proper adsorbents is 
very crucial since the adsorbent determines the effectiveness and inexpensiveness of an adsorption system and overall operation. ${ }^{7,8}$ In recent years, the search for renewable and low-cost adsorbents has become a hot topic in adsorption studies. Various lignocellulosic materials have been employed as alternative adsorbents for heavy metal removal from aqueous solutions. ${ }^{9}$ In this study, we utilized the sea mango (Cerbera manghas) fruit as a new adsorbent for the removal of $\mathrm{Cu}$ (II) and $\mathrm{Pb}$ (II) ions from an aqueous solution. Sea mango is a small evergreen coastal tree that can grow more than 10 metres in height. Sea mango trees can be easily found in most parts of Indonesia. Since the chemical components of dry sea mango fruits are lignin, cellulose, and hemicellulose, after pre-treatment, this lignocellulosic material can be utilized as an alternative adsorbent for heavy metal removal from water or wastewater. Both the single-compound and binary adsorption studies are relevant for the design, optimization, and operation of real water purification plants. In particular, the adsorption of heavy metal ions in multicomponent systems often appears as a strong antagonistic removal process since the properties and concentrations of ions can significantly modify the performances of adsorbents. ${ }^{10-12}$ Since the operating conditions can be potentially infinite in terms of combination of pollutant concentrations, the availability of reliable models to describe and/or predict the behavior of a certain adsorption system is an invaluable tool. In the literature, different models, such as the Langmuir model, ${ }^{13,14}$ modified competitive Langmuir model, ${ }^{13}$ extended Langmuir model, ${ }^{15,16}$ and Freundlich and extended Freundlich model, ${ }^{15}$ have been reported to theoretically describe the adsorption phenomena in both single-compound and binary systems. Except for the Langmuir model, all these models are empirical and take into account some descriptive aspects of adsorption, thus providing only a phenomenological explanation of the dynamics of the process. In particular, some fundamental details that define the way the adsorbates interact with the adsorbent surface and also with each other in multicomponent systems are rarely considered. For instance, the knowledge of the number of ions bonded per active site and the exact adsorbate position on the adsorbent surface with respect to the molecule shape can provide a direct explanation of the experimental adsorption capacity and the occurrence of any competitive effect, with full physical meaning.

In the present study, Hill and competitive Hill models, developed using an analytical theory mainly based on statistical physics, ${ }^{17}$ were applied to experimental adsorption isotherms of lead and copper on sea mango shells at different temperatures to provide new and interesting interpretations at the molecular level. The two statistical physics models allow the estimation of the number of ions bonded per active site, the adsorbate position, the density of the receptor sites, the saturation adsorbed quantity, and the molar adsorption energy. All the parameters were interpreted as functions of temperature and provided a deeper description of the single-compound and binary adsorption system. A new parameter based on the investigation of the number of ions bonded per site was also described to explain the inhibition effect arising in binary systems.

\section{Experimental}

Herein, a new adsorbent was produced from sea mango (Cerbera manghas) fruits. Raw fruits were obtained from the area near Widya Mandala Surabaya Catholic University, East Java, Indonesia. The fruits were dried in a force circulation oven (Memmert) until the moisture content was around $10 \%$. Subsequently, the dried sea mango fruits were pulverized until their particle size was around 80/100 mesh. Delignification of the sea mango powder was conducted using a sodium hydroxide solution $(2 \mathrm{M})$ at $60{ }^{\circ} \mathrm{C}$ for $3 \mathrm{~h}$ under constant stirring. After the delignification process was completed, the solid product was separated from the solution, washed several times with water treated by reverse osmosis, and dried at $105{ }^{\circ} \mathrm{C}$ for $24 \mathrm{~h}$. The pore characteristics of the pristine sea mango powder and delignified sea mango powder were measured using the nitrogen adsorption method. The measurements were conducted at the boiling point of nitrogen gas $\left(-196{ }^{\circ} \mathrm{C}\right)$ using Micromeritics ASAP 2010. Prior to the adsorption/ desorption measurements, the samples were degassed under vacuum conditions at $150{ }^{\circ} \mathrm{C}$. The BET surface area and pore volume of the pristine sea mango powder were $3.28 \mathrm{~m}^{2} \mathrm{~g}^{-1}$ and $0.01 \mathrm{~cm}^{3} \mathrm{~g}^{-1}$, respectively. After the delignification process, the surface area and pore volume of the sea mango powder increased to $15.74 \mathrm{~m}^{2} \mathrm{~g}^{-1}$ and $0.04 \mathrm{~cm}^{3} \mathrm{~g}^{-1}$, respectively. The BET surface area of sea mango is higher as compared to that of other biomasses such as rice straw $\left(1.23 \mathrm{~m}^{2} \mathrm{~g}^{-1}\right)$, fermented rice straw $\left(6.31 \mathrm{~m}^{2} \mathrm{~g}^{-1}\right),{ }^{18}$ Cucumis melo $\left(8.40 \mathrm{~m}^{2} \mathrm{~g}^{-1}\right),{ }^{19}$ and kraft lignin $\left(0.75 \mathrm{~m}^{2} \mathrm{~g}^{-1}\right) .{ }^{20}$

The $\mathrm{pH}_{\mathrm{pzc}}$ value of the sea mango was measured by a zeta meter (Zeta Potential Analyzer, Brookhaven 90Plus). The FTIR analysis of the pristine sea mango and metal-loaded sea mango was conducted using FTIR Shimadzu 8400S. The KBr method was employed to obtain the FTIR spectra. The FTIR spectra were obtained in the range from 4000 to $500 \mathrm{~cm}^{-1}$ (mid-IR wavenumber). The XRD analysis was conducted using a Philips X'pert X-ray diffractometer, and the patterns were acquired at $40 \mathrm{kV}$ and $30 \mathrm{~mA}$ using monochromatic high-intensity $\mathrm{CuK} \alpha_{1}$ $(\lambda=0.15405 \mathrm{~nm})$. The SEM images and EDX (energy dispersive $\mathrm{X}$-ray) spectra of the sea mango powder and metal-loaded sea mango were obtained using JEOL JSM-6500F. Before the analysis, the solid samples were coated with a thin layer of platinum under an argon atmosphere.

For single-compound adsorption, solutions of heavy metals at an initial concentration of $200 \mathrm{mg} \mathrm{L}^{-1}$ (for both $\mathrm{Cu}$ (II) and $\mathrm{Pb}(\mathrm{II})$ ) were prepared by dissolving a known amount of either $\mathrm{CuSO}_{4} \cdot 5 \mathrm{H}_{2} \mathrm{O}$ or $\mathrm{Pb}\left(\mathrm{C}_{2} \mathrm{H}_{3} \mathrm{O}_{2}\right)_{2} \cdot 3 \mathrm{H}_{2} \mathrm{O}$ in reverse osmosis (RO) water. The $\mathrm{pH}$ value of the solution was adjusted to 5. Singlecompound adsorption experiments were carried out at three temperatures $\left(30,40\right.$, and $50{ }^{\circ} \mathrm{C}$ ). To describe a complete adsorption isotherm, different masses of adsorbent (sea mango powder) were added to a series of Erlenmeyer flasks containing $100 \mathrm{~mL}$ of heavy metal solution. The Erlenmeyer flasks were then placed in a shaker water bath (Memmert) and shaken until equilibrium conditions were reached $(8-10 \mathrm{~h})$. The adsorption isotherms were obtained under equilibrium conditions, and 
time had no effect on the amount of metal uptake. Subsequently, the adsorbent was removed from the mixture by centrifugation (4000 rpm for $5 \mathrm{~min}$ ). The residual heavy metal concentration in the solution was analyzed using an atomic absorption spectrophotometer (Shimadzu). The amount of heavy metal adsorbed by the sea mango powder was calculated using the following equation:

$$
Q_{\mathrm{e}}=\frac{\left(C_{0}-C_{\mathrm{e}}\right)}{m} V
$$

where $C_{0}$ and $C_{\mathrm{e}}$ are the initial and equilibrium concentrations of heavy metal in the liquid phase $\left(\mathrm{mg} \mathrm{L}^{-1}\right)$, respectively, $V$ is the volume of the heavy metal compound solution (L), and $m$ is the mass of the adsorbent (g).

For the binary system, the heavy metal mixture was prepared by adding known amounts of both $\mathrm{CuSO}_{4} \cdot 5 \mathrm{H}_{2} \mathrm{O}$ and $\mathrm{Pb}\left(\mathrm{C}_{2} \mathrm{H}_{3} \mathrm{O}_{2}\right)_{2} \cdot 3 \mathrm{H}_{2} \mathrm{O}$ to $1 \mathrm{~L}$ of $\mathrm{RO}$ water to reach an initial concentration of both metals equal to $200 \mathrm{mg} \mathrm{L}^{-1}$. We used the same concentration of metals to obtain a better understanding about the competition for the adsorption active sites. Adsorption isotherm experiments were conducted based on the same abovementioned procedure.

\section{Characterization of the adsorbent and metal-loaded adsorbent}

The $\mathrm{pH}_{\mathrm{pzc}}$ ( $\mathrm{pH}$ at point zero charge) value of the sea mango was 4.2. At a $\mathrm{pH}$ below $\mathrm{pH}_{\mathrm{pzc}}$, the surface of the sea mango was positively charged, whereas at a $\mathrm{pH}$ above the $\mathrm{pH}_{\mathrm{pzc}}$, the surface of the sea mango was negatively charged. The negative surface charge of the sea mango enhances the uptake of metal cations from the solution. For this reason, the adsorption experiments were conducted at $\mathrm{pH} 5$.

The FTIR spectra of the pristine sea mango and $\mathrm{Cu}$ and $\mathrm{Pb}$-loaded sea mango are shown in Fig. 1. The adsorption characteristics of heavy metal on cellulosic material were observed at the wavenumbers $3405,2918,1375$, and $889 \mathrm{~cm}^{-1}$. The broad stretching absorption peak at around $3405 \mathrm{~cm}^{-1}$ represents bound - $\mathrm{OH}$ groups. After the adsorption process, this peak shifted to $3423 \mathrm{~cm}^{-1}$ for $\mathrm{Cu}$ (II) and $3435 \mathrm{~cm}^{-1}$ for $\mathrm{Pb}$ (II). The band at $2918 \mathrm{~cm}^{-1}$ is characteristic of the stretching vibration of $-\mathrm{CH}_{2}$. For the Cu-loaded sea mango, this band shifted to $2912 \mathrm{~cm}^{-1}$, whereas for the Pb-loaded sea mango, the shift to $2931 \mathrm{~cm}^{-1}$ was observed. After exposure to heavy metals, the peaks at $1375 \mathrm{~cm}^{-1}(\mathrm{CH})$ and $889 \mathrm{~cm}^{-1}$ (non-symmetric out-phase ring) also shifted to 1369 and $901 \mathrm{~cm}^{-1}$ for Cu-loaded sea mango and 1363 and $902 \mathrm{~cm}^{-1}$ for Pb-loaded sea mango, respectively. The shifting of these wavenumbers indicates that several functional groups are involved in the adsorption process. A complex formation between some surface functional groups and the metal occurred during the adsorption process.

The SEM images of the sea mango and its metal-loaded forms are depicted in Fig. 2. In general, the adsorption of $\mathrm{Cu}$ (II) and $\mathrm{Pb}$ (II) onto sea mango did not change the surface topography of the adsorbent. The EDX spectra of sea mango and its

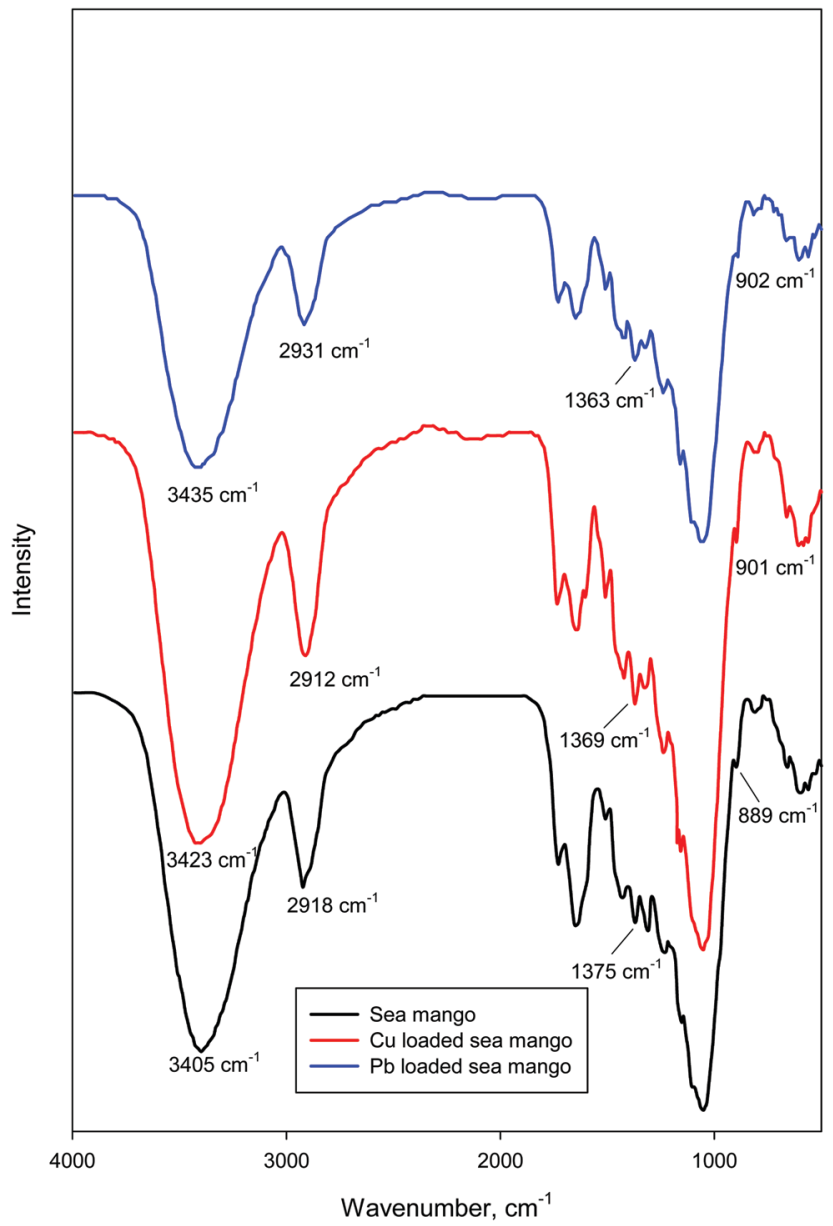

Fig. 1 FTIR spectra of sea mango and metal-loaded sea mango.

metal-loaded forms are also shown in Fig. 3. The EDX spectra of the $\mathrm{Cu}$ and $\mathrm{Pb}$-loaded sea mango indicate that a substantial amount of $\mathrm{Cu}$ and $\mathrm{Pb}$ has been adsorbed on the surface of the adsorbent. The $\mathrm{Cu}$ and $\mathrm{Pb}$ peaks have been detected after the adsorption process, which indicate that copper and lead ions may attach to some surface functional groups of the sea mango. High percentages of $\mathrm{C}, \mathrm{O}$, and $\mathrm{N}$ in sea mango and its metalloaded forms suggest that these elements are the building blocks of biomass.

X-ray diffraction patterns of the sea mango before and after $\mathrm{Cu}$ (II) and $\mathrm{Pb}$ (II) adsorption are shown in Fig. 4. New diffraction peaks were observed for both $\mathrm{Cu}$ and $\mathrm{Pb}$-loaded sea mango. For $\mathrm{Cu}$-loaded sea mango, new peaks appear at the $2 \theta$ values around $14.11^{\circ}, 27.12^{\circ}$, and $30.38^{\circ}$, whereas for Pb-loaded sea mango, the peaks appear at the $2 \theta$ values around $24.65^{\circ}, 26.60^{\circ}$, and $35.31^{\circ}$. The appearances of new peaks in the XRD spectra indicate the formation of copper or lead-containing substances.

\section{Adsorption isotherms in the single-compound and binary system}

Methodologically, before interpreting the single and binary adsorption process through the parameters appearing in the 

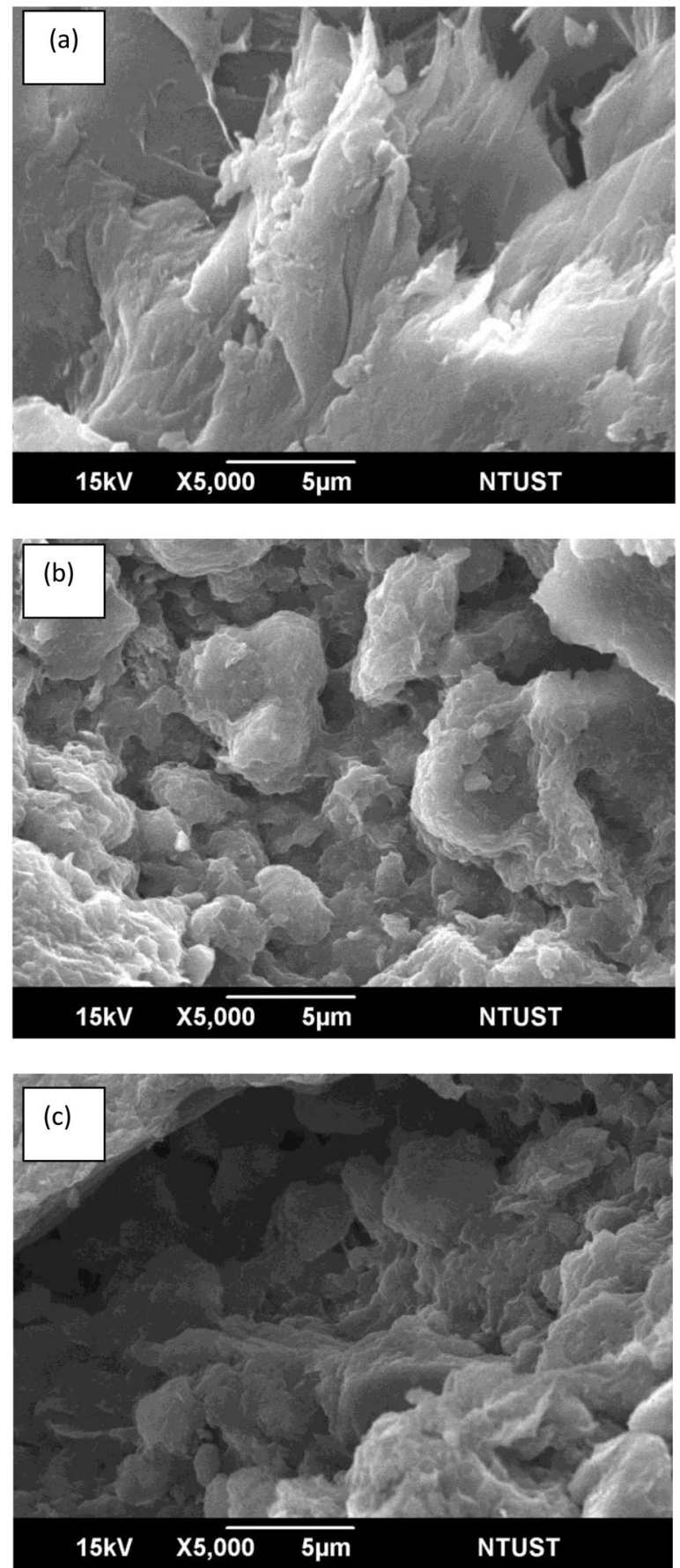

Fig. 2 SEM images of (a) sea mango, (b) Cu-loaded sea mango, and (c) $\mathrm{Pb}$-loaded sea mango.

statistical physics models, it is important to describe the profile of the adsorption isotherms and explain the corresponding phenomenon. Adsorption isotherms in both the singlecompound and binary systems are shown in Fig. 5 .

Experimentally and based on Fig. 5, the adsorption isotherms show a classical behavior in relation to the monotonic increase of the adsorbed capacity as a function of equilibrium concentration. The increase in this quantity indicates that the treated sea mango adsorbent accepts the necessary number of ions bonded per site,
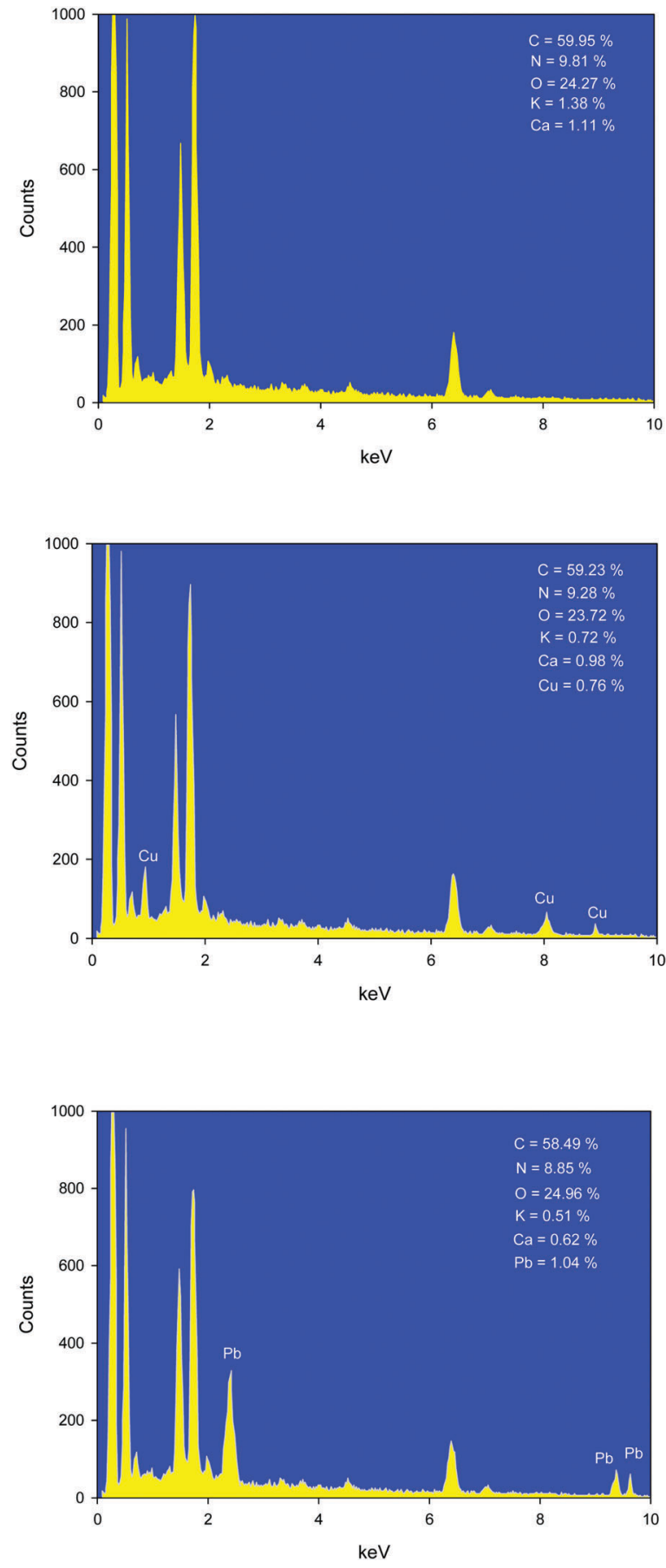

Fig. 3 EDX spectra of sea mango and its metal-loaded forms.

and finally, a number of receptor sites are occupied, which in some cases appear to be the maximum possible (asymptote). Moreover, the adsorption data show that the adsorption of $\mathrm{Pb}$ (II) is more than that of $\mathrm{Cu}$ (II) in both the single-compound and binary systems. This ranking is retained for all the investigated temperatures. It is interesting to observe that in the binary system, the adsorption capacity of both ions significantly decreases to values approximately equal to half of their corresponding values retrieved in the single-compound systems. Moreover, for this evidence, the behavior is the same at all 


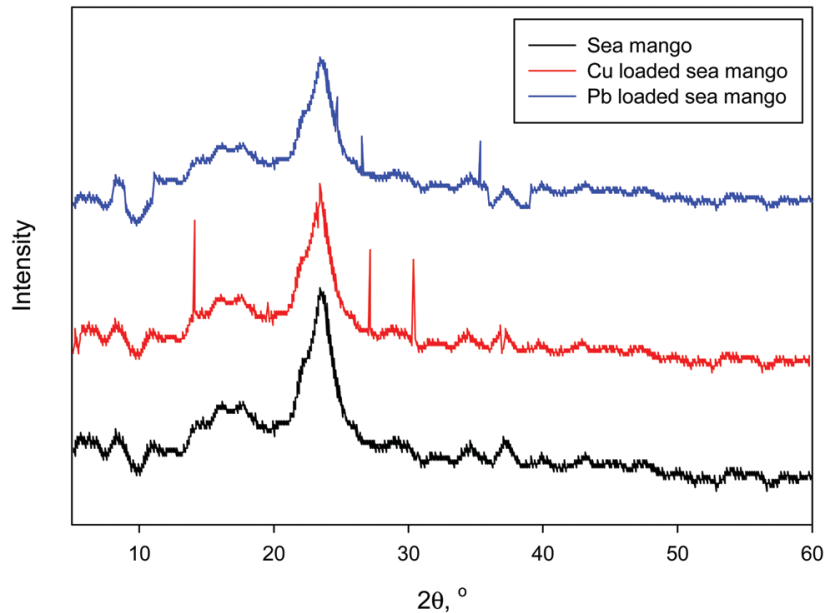

Fig. 4 XRD spectra of sea mango and heavy metal-loaded sea mango.

the investigated temperatures; this testifies the occurrence of strong competition phenomena during simultaneous adsorption. Finally, it is evident that in all the investigated systems and under the experimental conditions tested, adsorption is enhanced with the increasing temperature. To theoretically explain the physical phenomena involved in the adsorption of $\mathrm{Pb}$ (II) and $\mathrm{Cu}$ (II) in the single-compound and binary systems, two statistical physics models ${ }^{17}$ were applied, providing new interpretations at the molecular level. The main parameters affecting the single-compound and binary adsorption retrievable from the statistical physics treatment of the experimental data, i.e., the number of ions bonded per site and the adsorption energy, were used for the interpretation of the experimental evidence.

\subsection{Models for single-compound and binary adsorption}

For a complete theoretical description of the single-compound and binary adsorption phenomena, many conventional theories have been developed. Among them, the most tested theories are the Langmuir and competitive Langmuir models. These models were constructed based on easy assumptions, e.g., the receptor sites are energetically identical regardless of the adsorbate considered. Furthermore, they speculate that a localized adsorbent receptor site accommodates one adsorbate per active site. In terms of interactions, Langmuir and competitive Langmuir models neglect any interactions among adsorbates. Despite these models being successfully used in many studies, they present a serious drawback, which is not related to the mathematical form of the equation, but it concerns the assumptions made and their consequence in the interpretation of the results. These simple assumptions produced models in which the adsorption parameters did not have a physical meaning or just provided average values of the properties that did not help to fully understand the adsorption phenomena. To overcome these
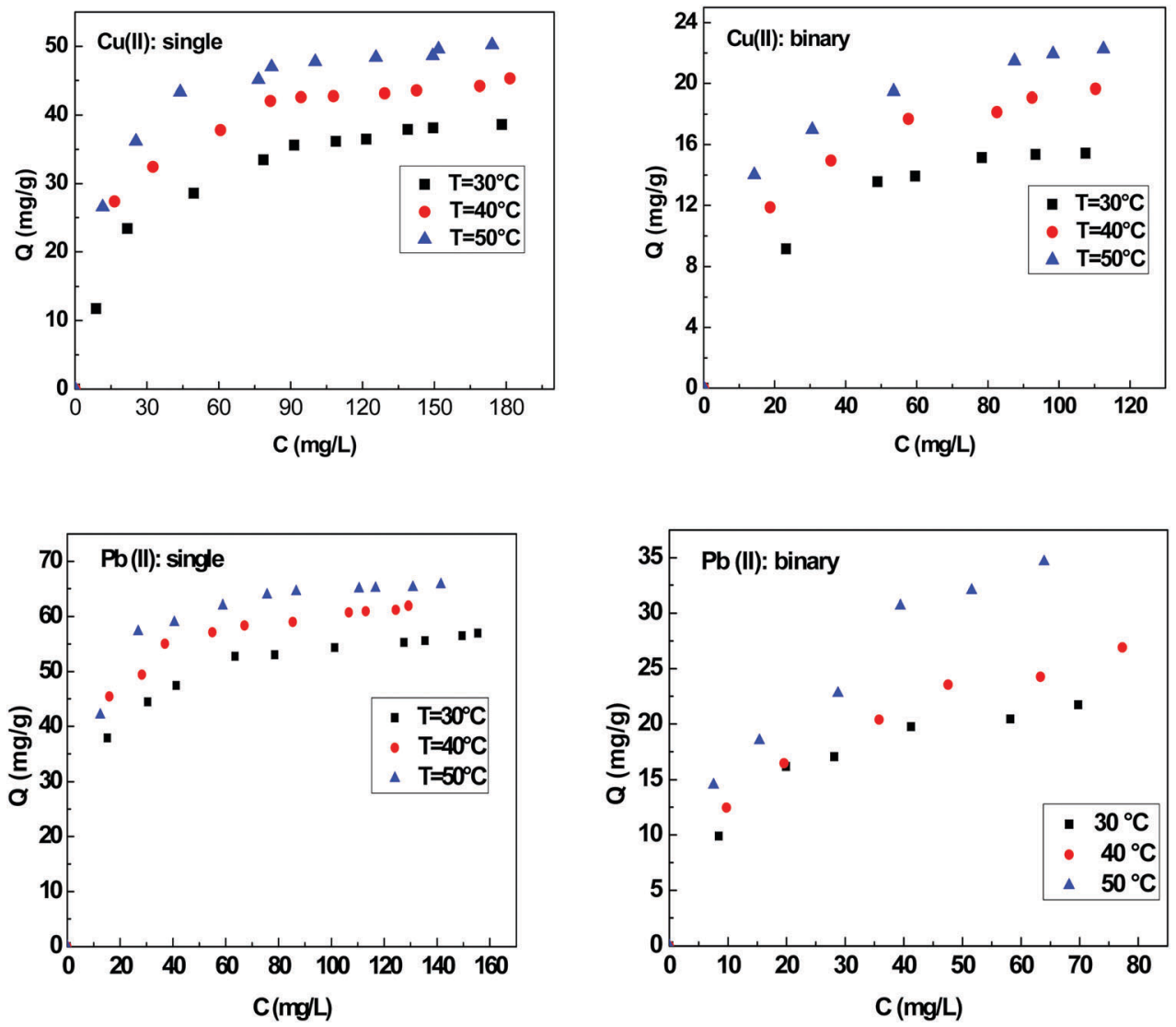

Fig. 5 Adsorption isotherms of copper and lead ions on sea mango shell in single-compound and binary systems $\left(\mathrm{pH} 5, T=30,40\right.$, and $\left.50{ }^{\circ} \mathrm{C}\right)$. 
limitations, we have recently developed interesting models for single-compound and binary adsorption on the basis of the grand canonical ensemble in statistical physics. Among these models, Hill ${ }^{17}$ and competitive Hill models ${ }^{17}$ might have a good impact on this study. The strong difference between the empirical models and the last cited models is that all the parameters of the Hill and competitive Hill models have a defined physical meaning; this is the main advantage of the statistical physics models as compared to that of the empirical models. Additionally, the Hill and competitive Hill models represent the general case of the Langmuir and competitive Langmuir models. Indeed, the Langmuir and competitive Langmuir models assume that each active site of the adsorbent accepts one ion/molecule, whereas the Hill and competitive Hill models assume that each active site of the adsorbent can accept $n$ or $n_{i}(i=1,2)$ ion/molecules. Moreover, these parameters vary with temperature; hence, it is worthy to briefly describe the model development.

\subsection{Hill model for single adsorption}

To construct the Hill model, we speculated that the receptor sites of the treated sea mango shell are energetically identical. Based on this energetic consideration, it has been supposed that a receptor site $(S)$ is characterized by a defined $(\varepsilon)$ energy, ${ }^{21}$ and it accepts $n$ variable number of ions. When the adsorption saturation condition is reached, a certain number of receptor sites are occupied by lead $\left(\mathrm{A}^{2+}\right)$ or copper ions $\left(\mathrm{B}^{2+}\right)$. For this reason, we consider that this number of receptor site is $N_{\mathrm{M}}$. Chemically, we can describe the single adsorption process by the following pseudo-reactions: ${ }^{21}$

$$
\begin{aligned}
& n \mathrm{~A}^{2+}+\mathrm{S} \rightleftarrows \mathrm{A}_{n}{ }^{2+} \mathrm{S} \\
& n \mathrm{~B}^{2+}+\mathrm{S} \rightleftarrows \mathrm{B}_{n}{ }^{2+} \mathrm{S}
\end{aligned}
$$

where $\mathrm{A}_{n}{ }^{2+} \mathrm{S}$ and $\mathrm{B}_{n}{ }^{2+} \mathrm{S}$ represent the formed complex (adsorbate-adsorbent), $n$ is the number of ions bonded per receptor site on the adsorbent surface.

Based on the grand canonical ensemble definition in statistical physics, the partition function of one identical site is written as follows: ${ }^{21,22}$

$$
z_{\mathrm{gc}}=1+\mathrm{e}^{\beta(\varepsilon+\mu)}
$$

Herein, two meaningful terms are included in the partition function: $\varepsilon$ represents the adsorption energy of the receptor site, $\mu$ represents the chemical potential of the receptor site, and $\beta$ is the Boltzmann factor. As abovementioned, the partition function is simple and contains only two energetic parameters $(\varepsilon$ and $\mu$ ); hence, it is reasonable to attain a simple formulation of the Hill model, which expresses the evolution of the adsorption capacity as a function of heavy metal equilibrium concentration $\left(c_{\mathrm{e}}\right)$, as given by the following expression: $:^{21,22}$

$$
Q=\frac{n N_{\mathrm{M}}}{1+\left(\frac{c_{1 / 2}}{c_{\mathrm{e}}}\right)^{n}}
$$

In this expression, $Q$ represents the adsorption capacity of the heavy metal and $c_{1 / 2}$ and $c_{\mathrm{e}}$ are the concentrations at half saturation and at equilibrium of heavy metal, respectively.

\subsection{Competitive Hill model for binary adsorption}

To describe the competitive effect between ions, it is speculated that these ions interact at the same type of receptor site and this site exclusively accepts lead and copper ions. ${ }^{17}$ Herein, two energies were considered for the competitive Hill model notation $\left(\varepsilon_{1}\right)$ and $\left(\varepsilon_{2}\right)$, describing the interactions between the receptor site and either lead or copper ions, respectively. ${ }^{17}$ Moreover, two binary pseudo adsorption reactions explaining the competitive effect between the studied ions can be written as follows: ${ }^{17}$

$$
\begin{aligned}
& n_{1} \mathrm{C}^{2+}+\mathrm{S} \rightleftarrows \mathrm{C}_{n_{1}}{ }^{2+} \mathrm{S} \\
& n_{2} \mathrm{D}^{2+}+\mathrm{S} \rightleftarrows \mathrm{D}_{n_{2}}{ }^{2+} \mathrm{S}
\end{aligned}
$$

where $\mathrm{C}^{2+}$ and $\mathrm{D}^{2+}$ represent $\mathrm{Pb}^{2+}$ and $\mathrm{Cu}^{2+}$ ions and $n_{1}$ and $n_{2}$ are the number of ions bonded per receptor site, respectively.

The partition function of the described receptor site can be expressed as follows: ${ }^{17}$

$$
z_{\text {gc }}=1+\mathrm{e}^{\beta\left(\varepsilon_{1}+\mu_{1}\right)}+\mathrm{e}^{\beta\left(\varepsilon_{2}+\mu_{2}\right)}=T_{1}+T_{2}+T_{3}
$$

Unlike the expression of the single-compound Hill model, this partition function of the competitive Hill model is more complicated because it contains three terms. The first term $\left(T_{1}\right)$ indicates that the receptor site cannot be occupied (empty) and $T_{2}+T_{3}$ explain the occupation of the receptor site by two ions. $\mu_{1}$ and $\mu_{2}$ represent the chemical potentials of $\mathrm{Pb}^{2+}$ and $\mathrm{Cd}^{2+}$ ions at the receptor site, respectively. Under these hypotheses, the competitive Hill model expressing the evolution of adsorption capacity as a function of heavy metal equilibrium concentrations $\left(c_{\mathrm{e}_{1}}\right.$ and $\left.c_{\mathrm{e}_{2}}\right)$ is written as follows: ${ }^{17}$

$$
\begin{gathered}
Q_{\mathrm{a} 1}=\frac{n_{1} N_{\mathrm{M}}\left(\frac{c_{\mathrm{e}_{1}}}{c_{01}}\right)^{n_{1}}}{1+\left(\frac{c_{\mathrm{e}_{1}}}{c_{01}}\right)^{n_{1}}+\left(\frac{c_{\mathrm{e}_{2}}}{c_{02}}\right)^{n_{2}}} \\
Q_{\mathrm{a} 2}=\frac{n_{2} N_{\mathrm{M}}\left(\frac{c_{\mathrm{e}_{2}}}{c_{02}}\right)^{n_{2}}}{1+\left(\frac{c_{\mathrm{e}_{1}}}{c_{01}}\right)^{n_{1}}+\left(\frac{c_{\mathrm{e}_{2}}}{c_{02}}\right)^{n_{2}}}
\end{gathered}
$$

where $N_{\mathrm{M}}$ is the density of the receptor site; $c_{01}$ and $c_{02}$ represent the concentrations at half saturation of each adsorbate; $c_{\mathrm{e}_{1}}$ and $c_{\mathrm{e}_{2}}$ are the heavy metal equilibrium concentrations.

A simple fitting method based on the Levenberg-Marquardt algorithm $^{23}$ shows a good correlation between the statistical physics models and the experimental data in single-compound and binary systems. Indeed, the values of the correlation coefficient $R^{2}$ measuring the fitting quality vary from 0.975 to 0.994 and from 0.971 to 0.992 in the single-compound and binary system, respectively. Additionally, the fitting method provides all the values of the model parameters at different 
Table 1 Adsorption parameters in single-compound and binary systems deduced by the Hill and competitive Hill models

\begin{tabular}{|c|c|c|c|c|c|c|}
\hline & \multicolumn{3}{|c|}{$\mathrm{Pb}$ (II):single } & \multicolumn{3}{|c|}{ Cu(II):single } \\
\hline & $30^{\circ} \mathrm{C}$ & $40{ }^{\circ} \mathrm{C}$ & $50{ }^{\circ} \mathrm{C}$ & $30^{\circ} \mathrm{C}$ & $40{ }^{\circ} \mathrm{C}$ & $50{ }^{\circ} \mathrm{C}$ \\
\hline$n$ & 1.02 & 1.44 & 1.98 & 1.01 & 1.28 & 1.74 \\
\hline$Q_{\text {sat }}\left(\mathrm{mg} \mathrm{g}^{-1}\right)$ & 58.11 & 64.08 & 67.12 & 39.25 & 49.44 & 52.17 \\
\hline \multirow[t]{3}{*}{$N_{\mathrm{M}}$} & 56.97 & 44.44 & 33.83 & 39.18 & 38.28 & 29.88 \\
\hline & \multicolumn{3}{|c|}{$\mathrm{Pb}$ (II):binary } & \multicolumn{3}{|c|}{$\mathrm{Cu}(\mathrm{II})$ :binary } \\
\hline & $30{ }^{\circ} \mathrm{C}$ & $40{ }^{\circ} \mathrm{C}$ & $50{ }^{\circ} \mathrm{C}$ & $30^{\circ} \mathrm{C}$ & $40{ }^{\circ} \mathrm{C}$ & $50{ }^{\circ} \mathrm{C}$ \\
\hline$n_{i}$ & 0.50 & 0.55 & 0.38 & 0.37 & 0.28 & 0.33 \\
\hline$Q_{\text {sat }}\left(\mathrm{mg} \mathrm{g}^{-1}\right)$ & 26.11 & 33.12 & 42.11 & 17.12 & 22.18 & 27.21 \\
\hline$N_{\mathrm{M}}$ & 52.12 & 60.21 & 110.81 & 46.27 & 79.21 & 81.23 \\
\hline
\end{tabular}

temperatures, as summarized in Table 1. An example of the adsorption isotherm fitting is reported in the Appendix.

\section{Hill and competitive Hill model parameter interpretation}

\subsection{Number of ions bonded per site $\left(n\right.$ and $\left.n_{i}\right)$}

The $n$ and $n_{i}(i=1,2)$ parameters balancing the pseudo-reactions (eqn (2) and (5)) are characterized by physical and chemical aspects, which play many important roles in the singlecompound and binary adsorption studies. Based on the scientific literature and to the best of our knowledge, the position of copper and lead ions on the adsorbent surface upon adsorption has not described to date regardless of the studied adsorbent. These two parameters are able to provide useful information about the position at each temperature by a systematic method. In our recent study, two interesting cases were described to know the position of the adsorbate (ions/molecules) on the adsorbent surface. It is a simple method and applicable for any adsorption system. The first case describes a parallel position on the adsorbent if the number of ions bonded per site is lower than 1 , i.e., the ions interact with a minimum of two receptor sites (multi-link). ${ }^{21-23}$ The second case assumes a perpendicular position if the $n$ and $n_{i}$ values are higher than 1, i.e., a receptor site is occupied by at least one ion. ${ }^{21-23}$ Based on the fitting results (Table 1 ), in the single-compound systems, the $n$ parameter values are higher than 1 for all the temperatures and for both adsorbates; however, in the binary adsorption system, the contrary is observed. From these results, it was determined that copper and lead ions were bonded in a perpendicular position on the treated sea mango in single-compound systems, whereas in the binary systems, they were bonded in a parallel position. As an explicative example, the $n$ parameter value of $\mathrm{Pb}^{2+}$ at $30{ }^{\circ} \mathrm{C}$ in the single-compound system is 1.02 , whereas in the binary system, this parameter value is reduced to 0.50 . This indicated that $\mathrm{Pb}^{2+}$ ion was bonded practically with one receptor site in the single-compound system, but by two receptor sites in the binary system. This result allows for hypothesizing a mechanism of adsorption of two ions on the adsorbent. In fact, an electrostatic interaction between cations and the adsorbent surface appears to be most probable because of the demonstrated competition effects between ions of the same charge and the higher number of receptor sites necessary to bind lead in the binary system. The latter evidence testifies that a preferential adsorption with copper ions occurs. and for this reason, a higher number of receptor sites is necessary to bind one lead ion (i.e., a weaker interaction with lead makes it necessary to bind to more active sites). This conclusion finds support in the energetic characterization of the adsorption systems, as reported hereinafter.

The evolution of the $n$ and $n_{i}$ parameters as a function of temperature is depicted in Fig. 6.

Based on this evolution, it can be seen that the number of ions bonded per site (in the single-compound system) has a linear trend with temperature; this reflects that the thermal agitation effect is the dominant factor, which explains this behavior. ${ }^{24}$ With regard to the evolution of the $n_{i}$ parameter with temperature in the binary system, the behavior is less simple and not monotonic for both ions due to specific physical interactions. When the number of copper ions bonded per site increases, the number of lead ions bonded per site decreases. This evolution is mainly due to the competitive effect of these ions for the same receptor site. Hence, an inhibition effect is created between these ions, i.e., a partial exclusion. For a possible explanation of this inhibition effect, it is useful to observe that when lead ion (for example) interacts
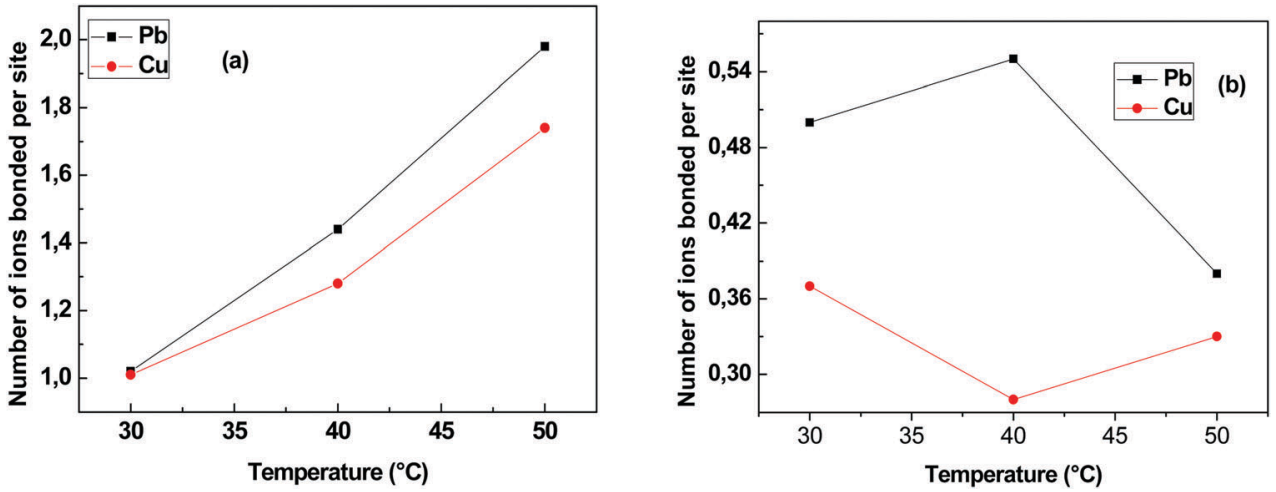

Fig. 6 Temperature effect on the number of ions bonded per site in the single (a) and binary system (b). 
with two receptors sites, the presence of copper ion can hide these receptor sites.

The Hill and competitive Hill models provide explanation of the competition between ions for the same receptor site by introducing a new parameter. This new parameter is defined as follows: $n_{\mathrm{b}} / n_{\mathrm{s}}$ (or $\left.n_{i} / n\right)$ where $n_{\mathrm{s}}$ and $n_{\mathrm{b}}$ are the number of ions of the same metal bonded per site in the singlecompound and binary systems, respectively. In the systems under analysis, all the values of this ratio were lower than 1 . This result indicated that the number of ions bonded per site was reduced from the single to binary adsorption system; this reflected the competitive effect. It was concluded that a visible interaction was established between two ions at the same receptor site.

Finally, a comparison with the literature models (e.g. Langmuir and extended Langmuir models) showed interesting differences. In fact, these models assume that the adsorbent active site can bind one ion regardless of the adsorbate nature. In our study, the models suppose that the adsorbent can bind a variable number ( $n$ and $n_{i}$ ) of ions in the single-compound and binary systems; this appears to be most representative of the occurring phenomena. Herein, we reiterate that it is very useful to estimate the number of ions bonded per site to facilitate the understating of the adsorption phenomena.

\subsection{Density of the receptor sites}

When saturation is reached, a number of receptor sites are completely occupied $\left(N_{\mathrm{M}}\right)$.

The evolution of this parameter with temperature is depicted in Fig. 7 for both metals and both the single-compound and binary systems.

It can be clearly observed that the receptor site density is influenced by temperature. For the single adsorption system, when the temperature increases, the density decreases and this is probably due to thermal collisions. ${ }^{24}$ The opposite behavior was observed in the binary system. The increase of density in the binary system can be explained by the absence of the steric hindrance effect between ions at the same receptor site. When the steric hindrance effect is neglected, it is possible that many new receptor sites appear for the adsorption of the ions.

\subsection{Evaluation of adsorption capacity at saturation in the single-compound and binary systems}

The saturation adsorption capacity represents one of the most meaningful parameters describing the single-compound and binary adsorption systems as it provides invaluable information about the performance limits of an adsorbent. In Fig. 8, the
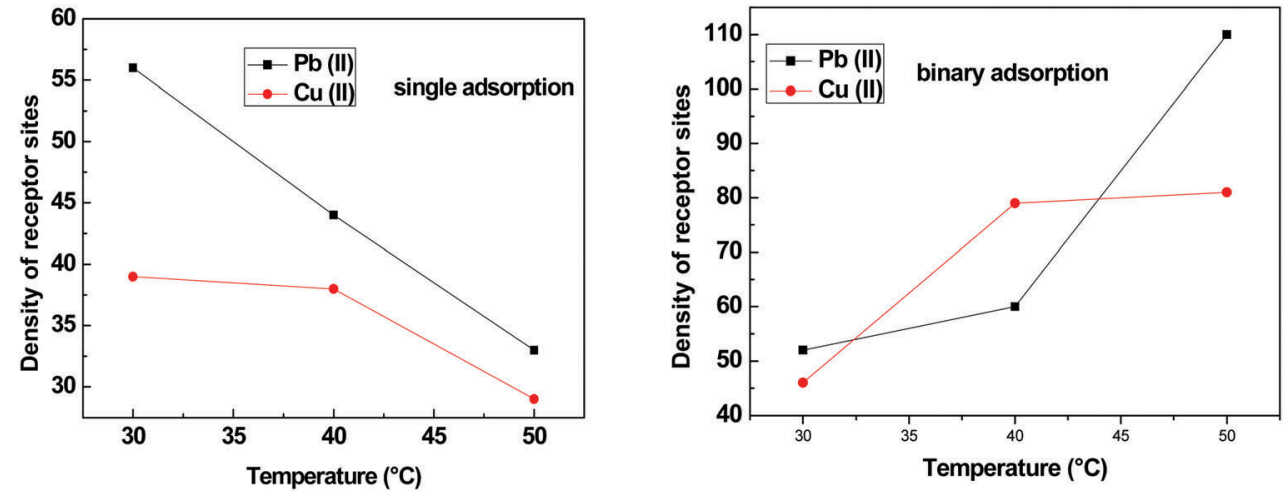

Fig. 7 Evolution of density of receptor sites as function of temperature in single-compound (left) and binary (right) adsorption.
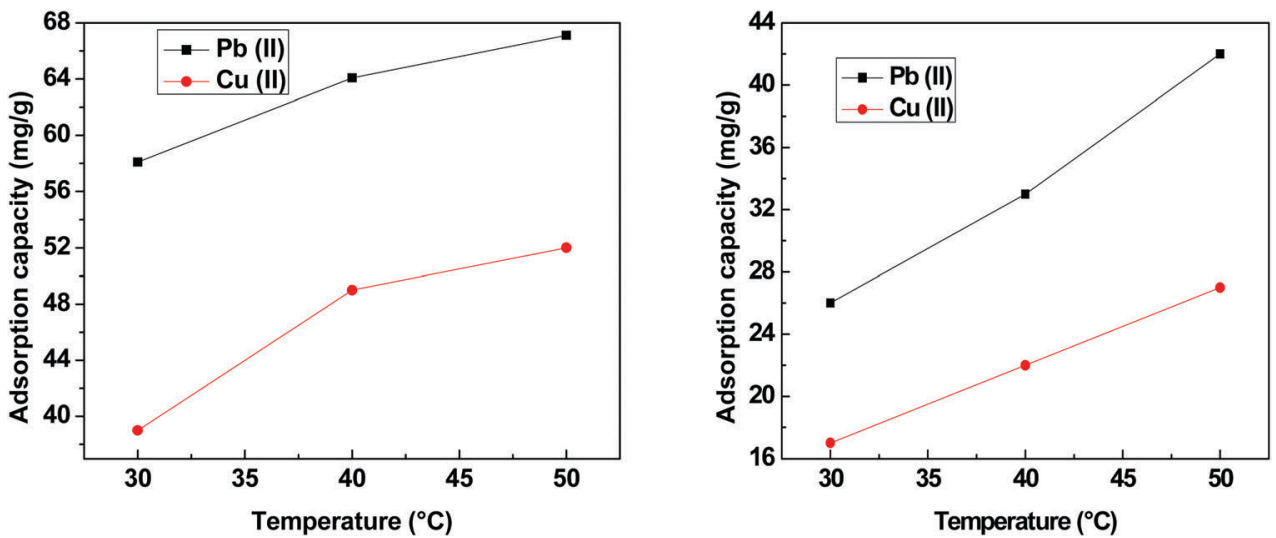

Fig. 8 Saturation adsorption capacity of copper and lead ions in the single-compound (left) and binary (right) system as a function of temperature. 
saturation adsorption capacity is depicted as a function of temperature for all the investigated experimental conditions.

A clear dependence of this parameter on temperature is observed in Fig. 6 and is more clearly illustrated in Fig. 8, which shows that the adsorption capacity increases when the temperature increases. This evolution type reflects that the temperature promotes the adsorption of lead and copper ions on treated sea mango; hence, single-compound and binary adsorption have an endothermic character. It was noted that the adsorption capacity value in the binary system was reduced as compared to that of the single-compound counterpart. For example, for $\mathrm{Cu}^{2+}$, this quantity is $38 \mathrm{mg} \mathrm{g}^{-1}$ at $T=30{ }^{\circ} \mathrm{C}$ in the single-compound system, whereas in the binary system, it is reduced to $18 \mathrm{mg} \mathrm{g}^{-1}$ at the same temperature. This means that the $\mathrm{Cu}^{2+}$ adsorption capacity was reduced by about $47 \%$. As abovementioned in Section 5.1, an evident interaction was established between two ions at the same receptor site. To describe and quantify this interaction effect, it is necessary to determine the ratio between the adsorption capacity at saturation in the binary system and the corresponding (i.e. same) ion in the singlecompound system. ${ }^{25}$

- $Q_{\mathrm{b}} / Q_{\mathrm{s}}=1$ : there is no significant interaction between lead and copper ions.

- $Q_{\mathrm{b}} / Q q_{\mathrm{s}}>1$ : adsorption of copper ion is promoted by the presence of lead ion or the inverse.

- $Q_{\mathrm{b}} / Q_{\mathrm{s}}<1$ : the adsorption of copper ion is affected by copper ions or the inverse.

For both ions, $Q_{\mathrm{s}}$ was higher than $Q_{\mathrm{b}}$ at each temperature; thus, the ratio was lower than 1 . In conclusion, this result demonstrated that an inhibition effect was established between lead and copper ions at the same site of the treated sea mango shell.

\section{Adsorption energy and comparative study}

The adsorption energy parameter represents a tool to characterize the interactions of lead and copper ions with the adsorbent surface. Using the two expressions deduced from the Hill and competitive Hill models, the adsorption energies for the single-compound and binary systems were calculated at different temperatures as follows: ${ }^{17}$

$$
\begin{gathered}
\varepsilon=k_{\mathrm{B}} T \ln \left(\frac{c_{\mathrm{s}}}{c_{1 / 2}}\right) \\
\varepsilon_{\mathrm{i}}=k_{\mathrm{B}} T \ln \left(\frac{c_{\mathrm{si}}}{c_{\mathrm{i}}}\right)
\end{gathered}
$$

where $c_{\mathrm{si}}$ is the solubility of the heavy metal $\mathrm{i}$.

In Fig. 9, the calculated values for the investigated systems as a function of temperature are reported. The adsorption energy values varied from 8.66 to $37.14 \mathrm{~kJ} \mathrm{~mol}^{-1}$ in the single-compound system, whereas in the binary system, they ranged from 3.88 to $16.22 \mathrm{~kJ} \mathrm{~mol}^{-1}$. This evidence indicates that both the single-compound and binary adsorption processes occur by physisorption; ${ }^{17}$ however, the single-compound adsorption systems show high adsorption energy, which is similar to chemisorption. Based on our reported fitting results, it is clear that the adsorbed quantity of $\mathrm{Pb}^{2+}$ is greater as compared to that of $\mathrm{Cu}^{2+}$ at each temperature and in both the single-compound and binary systems. Classically and based on the reported studies, we can explain this difference by many reasons such as the differences in Pauling electronegativity ${ }^{26}$ and the ionic size of the adsorbates. ${ }^{26}$ However, apart from the classical interpretations, in light of the modelling analysis carried out, it is possible to attribute new explanations with regard to this behavior. In fact, as previously reported, our fitting results in the single-compound systems showed that the number of ions bonded per $\mathrm{Pb}^{2+}$ site was higher than the number of $\mathrm{Cu}^{2+}$. Despite this number being reduced in the binary system, the receptor site of the adsorbent still prevalently accepted $\mathrm{Pb}^{2+}$ ions. In parallel, the adsorbed quantity was characterized by a similar behavior in the single-compound and binary system, i.e., the adsorbed quantity of $\mathrm{Pb}^{2+}$ was greater than that of $\mathrm{Cu}^{2+}$ in single-compound systems, and besides a reduction, the same behavior was observed in the binary system. Interestingly, the adsorption energy showed the same qualitative trend with temperature as the adsorbed quantity in the singlecompound and binary systems. Indeed, the $\mathrm{Pb}^{2+}$ adsorption energy is greater than the $\mathrm{Cu}^{2+}$ adsorption energy, and this energy is reduced in the binary system. Reasonably, it can be concluded
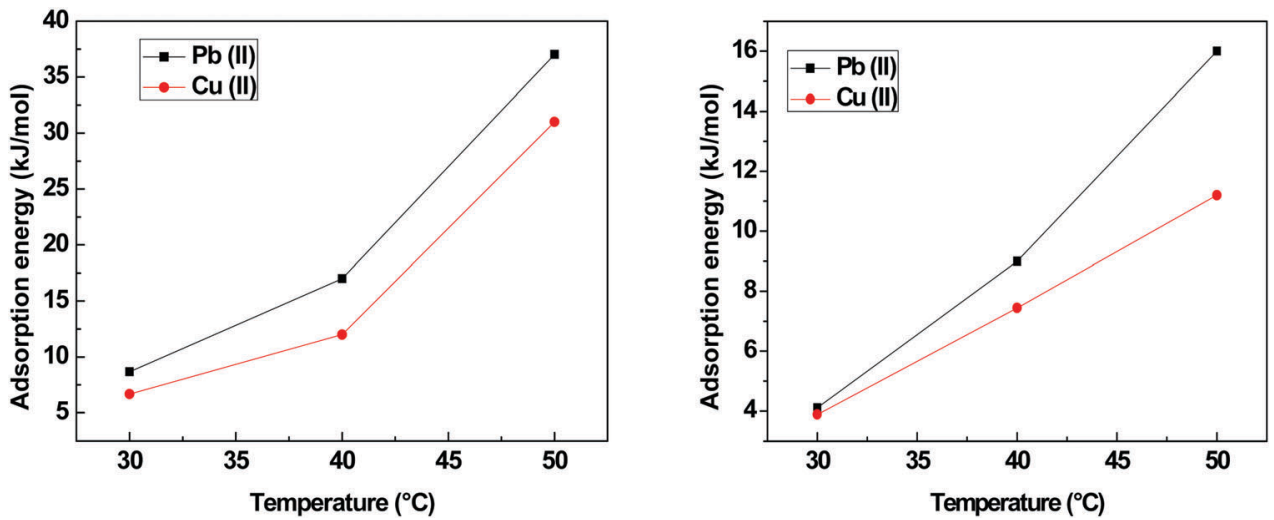

Fig. 9 Adsorption energy evolution in the single-compound (left) and binary (right) adsorption system as a function of temperature. 
that this energy is the dominant factor controlling the singlecompound and binary adsorption systems, favoring the adsorption of $\mathrm{Pb}^{2+}$ in both single-compound and binary systems. In conclusion, the reduction of the adsorbed quantity in the binary system is mainly due to the reduction in the adsorption energy.

\section{Conclusion}

Herein, the adsorption of $\mathrm{Pb}$ (II) and $\mathrm{Cu}(\mathrm{II})$ ions on the treated sea mango was studied as a function of the temperature in both single-compound and binary systems. Experimental results showed that the adsorption of $\mathrm{Pb}$ (II) was more than that of $\mathrm{Cu}(\mathrm{II})$ ions in both the single-compound and binary systems. Simultaneously, both ions experienced a significant reduction in the adsorption capacity in the binary system as compared to those in the single-compound system. Finally, under all the investigated conditions, adsorption seems to be promoted by an increase in temperature. To provide a meaningful explanation for this experimental evidence, a dedicated modelling
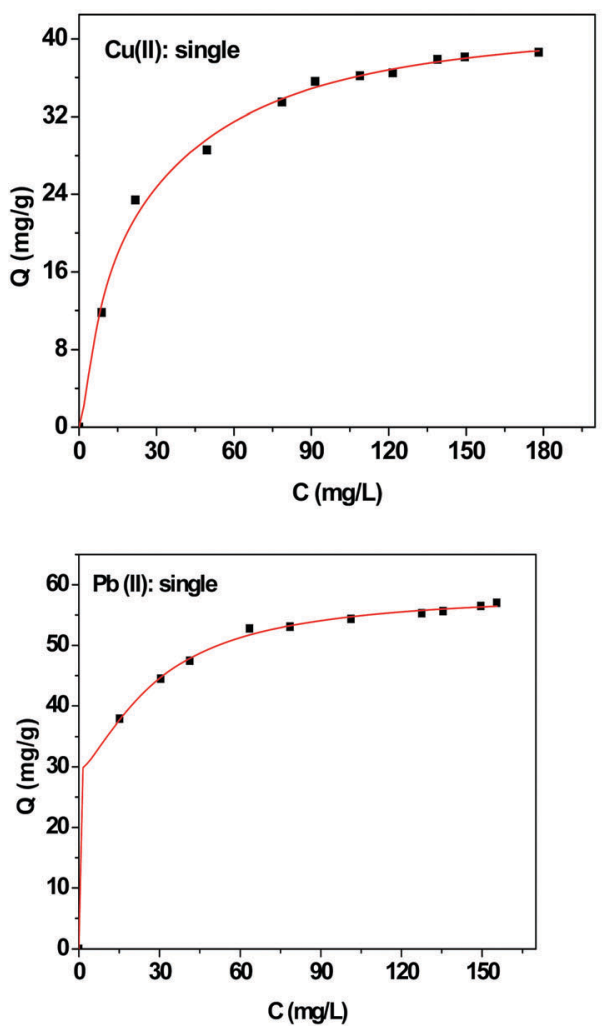

analysis was carried out and models, based on statistical physics, were derived.

In particular, the Hill and competitive Hill models developed using the statistical physics were applied to provide new and interesting interpretations of lead and copper ion adsorption on treated sea mango in the single-compound and binary systems. Using the model parameters, the adsorbate position of each bonded ion was described, and it was shown that the ions interacted by either the perpendicular or parallel position in the single or binary system, respectively, based on investigation of the number of ions bonded per site. The study of the same parameters explained that an inhibition effect appeared between ions for the same receptor site in the binary system with respect to the single-compound counterpart. The interpretation of the adsorbed quantity confirmed this inhibition effect and explained that the adsorbent was more selective for lead ions. Among the adsorption parameters, adsorption energy was found to be most significant as it represented the main factor controlling the extent of single-compound and binary adsorption.

\section{Conflicts of interest}

There are no conflicts to declare.

\section{Appendix}

Example of adsorption isotherm fitting in the single and binary systems.
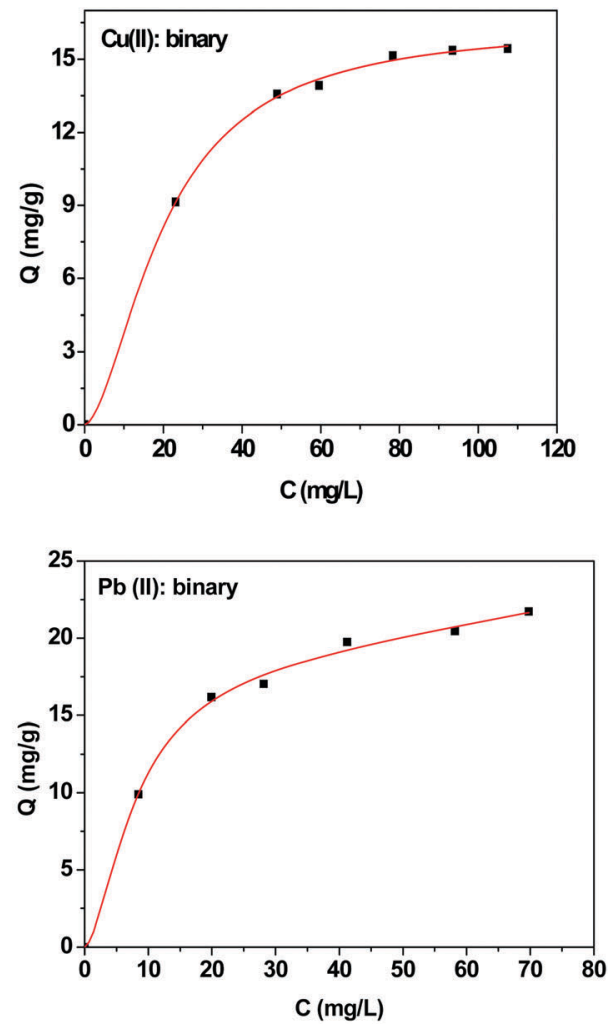

\section{References}

1 P. Iovino, S. Canzano, S. Capasso, A. Erto and D. Musmarra, Chem. Eng. J., 2015, 227, 360-367.

2 M. Benjamin, Water Chemistry, New York, 2nd edn, 2002.

3 F. Fenglian and Q. Wang, J. Environ. Manage., 2011, 92, 407-418.

4 S. Satyro, M. Race, Di. F. Natale, A. Erto, M. Guida and R. Marotta, Chem. Eng. J., 2016, 283, 1484-1493. 
5 G. J. D. M. Rocha, V. M. Nascimento, A. R. Gonçalves, V. F. N. Silva and C. Martín, Ind. Crops Prod., 2015, 64, 52-58.

6 Y. Pan, P. Cai, M. Farmahini-Farahani, Y. Li, X. Hou and H. Xiao, Appl. Surf. Sci., 2016, 358, 333-340.

7 A. Bhatnagar and M. Sillanpaa, Chem. Eng. J., 2010, 157, 277-296.

8 A. Erto, L. Giraldo, A. Lancia and J. C. M. Piraján, Water, Air, Soil Pollut., 2013, 224(4), 1531-1541.

9 S. Babel and T. A. Kurniawan, J. Hazard. Mater., 2003, 97, 219-243.

10 A. Erto, D. F. Natale, D. Musmarra and A. Lancia, Adsorption, 2015, 21(8), 611-621.

11 F. Bouhamed, Z. Elouear, J. Bouzid and B. Ouddane, Environ. Sci. Pollut. Res., 2016, 23, 15801-15806.

12 J. H. Park, O. S. Sik, S. H. Kim, J. S. Cho, R. D. Delaune and D. C. Seo, Chemosphere, 2016, 142, 77-83.

13 E. F. Soetaredjo, A. Kurniawan, O. L. Ki and S. Ismadji, Chem. Eng. J., 2013, 219, 137-148.

14 H. Muhamad, H. Doan and A. Lohi, Chem. Eng. J., 2010, 158, 369-377.

15 E. F. Soetaredjo, S. Ismadji, S. P. Santoso, O. L. Ki, A. Kurniawan and Y. H. Ju, Chem. Eng. J., 2013, 231, 406-413.
16 A. S. Luna, A. L. H. Costa, A. C. A. da. Costa and C. A. Henriques, Bioresour. Technol., 2010, 101, 5104-5111.

17 L. Sellaoui, M. Bouzid, L. Duclaux, L. Reinert, S. Knani and A. B. Lamine, $R S C A d v$., 2016, 6, 67701-67714.

18 J. Y. Wang, H. Cui, C. W. Cui and D. F. Xing, Ecol. Eng., 2017, 95, 793-799.

19 S. T. Akar, S. Arslan, T. Alp, D. Arslan and T. Akar, Chem. Eng. J., 2012, 185-186, 82-90.

20 M. B. Sciban, M. T. Klasnja and M. G. Antov, Ecol. Eng., 2011, 37, 2092-2095.

21 L. Sellaoui, H. Guedidi, S. Knani, L. Reinert, L. Duclaux and A. B. Lamine, Fluid Phase Equilib., 2015, 387, 103-110.

22 L. Sellaoui, N. Mechi, É. C. Lima, G. L. Dotto and A. B. Lamine, J. Phys. Chem. Solids, 2017, 109, 117-123.

23 L. Sellaoui, H. Guedidi, S. Masson, L. Reinert, J. M. Levêque, S. Knani, A. B. Lamine, M. Khalfaoui and L. Duclaux, Fluid Phase Equilib., 2016, 414, 156-163.

24 L. Sellaoui, G. L. Dotto, J. O. Gonçalves, L. A. A. Pinto, S. Knani and A. B. Lamine, J. Mol. Liq., 2016, 222, 151-158.

25 F. Qin, B. Wen, X. Q. Shan, Y. N. Xie, T. Liu, S. Z. Zhang and S. U. Khan, Environ. Pollut., 2006, 144, 669-680.

26 T. Depci, A. R. Kul and Y. Önal, Chem. Eng. J., 2012, 200-202, 224-236. 